\title{
PENSAR DESDE LA PROPIA HISTORIA. DE ESCUELA, PEDAGOGÍA Y
}

\author{
ALBERCAS (1) \\ Think from the story itself. School, pedagogy and pools \\ Pensar desde a própria história. De escola, pedagogia e albercas
}

\section{Marco Fidel Gómez Londoño (2)}

(1) Este artículo brota del proyecto de escritura "Los maestros cuentan" de la Secretaría de Educación de Medellín (2015). Corresponde a una versión de la publicación en mención.

(2) Universidad de Antioquia, Colombia. Cel. +57 $322 \quad 658 \quad 44 \quad 31$ Correo electrónico: $\underline{\text { marcosmar53@gmail.com }}$

\section{Resumen}

Hurgar en la propia historia permite enriquecer el suelo epistemológico, político y educativo de los maestros que conforman la escuela. Volver a las experiencias de antaño, hacerlas vivas, observarlas desde otros estrados, deconstruirlas desde una mirada crítica, quizá posibilite encontrar alternativas a prácticas que se asumen como naturalizadas. El presente artículo, afincado en un lenguaje narrativo en primera persona, pretende explorar la propia historia personal desde tres momentos específicos: infancia, llegada a la escuela pública y el encuentro con una red de maestros. A fuerza de voces se reflexionan distintos modos de educar desde temporalidades variadas; el cometido, entonces, pasa por el reconocimiento de mi historia personal como lumbrera en la tarea imperecedera de construir una sociedad más digna desde el escenario escolar.

Palabras clave: pedagogía, relato, maestros, escuela.

\begin{abstract}
Delving into own history enriches the epistemological, political and educational ground of teachers who make up the school. Return to the experiences of the past, make them alive, observe them from other stages, and deconstruct them from a critical perspective make possible, maybe, to find alternatives to the practices assumed as naturalized. This article, settledin a first-person narrative language, tries to explore the own personal history since three specific moments: childhood, coming to public school and meeting with a teacher network. By strength of different voices, ways of educating are reflected from
\end{abstract}


various temporalities. Then, the mission passes through the recognition of my personal history as light in everlasting task of building a more dignified society from the school setting.

Keywords: pedagogy, story, teachers, school.

\section{Resumo}

Remover na própria história permite enriquecer o solo epistemológico, político e educativo dos maestros que conformam a escola. Voltar às experiências de antanho, fazê-las vivas, observá-las desde outros estrados, deconstruirlas desde uma olhada crítica, quiçá possibilite encontrar alternativas a práticas que se assumem como naturalizadas. $\mathrm{O}$ presente artigo, estabelecido em uma linguagem narrativa em primeira pessoa, pretende explorar a própria história pessoal desde três momentos específicos: infância, chegada à escola pública e o encontro com uma rede de maestros. A força de vozes reflexionam-se diferentes modos de educar desde temporalidades variadas; o cometido, então, passa pelo reconhecimento de minha história pessoal como lumbrera na tarefa imperecível de construir uma sociedade mais digna desde o meio escolar.

Palavras-chave: pedagogia, história, professores, escola.

\section{A modo de presentación}

Gran parte del profesorado ya lo era desde niño ¿Quién no jugó con tiza y tablero? ¿Quién no tuvo cuadernos vencidos por el tiempo para hincharlos con nombres de caricaturas, de personajes, de familiares, de juguetes, de cuentos? ¿Quién no dibujó con los raídos colores del consumado año escolar? ¿Quién no contó historias ficticias para hacer de la quimera del adulto la gran realidad infantil? Yo lo hice. Era un niño con el talante de una edad que desconoce patrimonios de mayores. Yo era un profesor diminuto-lo digo por el tamaño del cuerpo que encarnaba- en una casa que me parecía grande, con gente inmensa.

Luego crecí, estudié en la Normal Superior de Medellín y en la Universidad de Antioquia. Allí seguí el camino de los juguetes, de los cuentos, de los colores, de las lecturas, de los recreos. También de las obligaciones y de las contrariedades. Ya la casa no 
parecía tan grande ni las personas tan inmensas. En un abrir y cerrar de ojos, pasé de mi casa a la escuela, y luego me convertí en maestro titulado.

En este artículo contaré aquel recorrido- desde el punto de vista personal- que conecta lugares, aromas, personas, hechos, experiencias, recuerdos y muchos maestros, en la configuración de un modo de ver la escuela y la educación. El recorrido biográfico se realizará desde tres momentos particulares: mi infancia, la llegada a una escuela pública y el encuentro con maestros desde un colectivo que coordino.

Escarbar en el pasado permite reconocer el presente desde una perspectiva humana, política y pedagógica. En ese sentido, reconstruir esta historia permite preguntarme por ¿quién soy?, ¿a quién le sirvo? y ¿cómo le sirvo ${ }^{1}$. Con Borges (2015), este relato me permite ir a una forma de ensoñación que indaga desde la palabra humana y que no puede escribirse de otra manera, pues no está en el verso ${ }^{2}$. Aquel verso convertido en amasijo de citas que, en no pocas ocasiones, desvirtúa y desfigura la voz personal para mudarla en voz cosmética ya “objetivada”. Desde ahí, una polifonía de voces acompañan el relato que enriquecen, a mi modo de ver, la escena educativa y pedagógica de mi vida.

\section{Una escuela que era una cebolla}

Allí arriba- donde el barrio es una foto congelada en el tiempo- la neblina corre sin acoso por la montaña regada de casas que parecen reproducirse al ritmo de su población. La organización abstracta insinúa que fue más por necesidad que por arte la ubicación de cada una de ellas. Es muy temprano en la mañana. Llovió con intensidad y el frío que impera parece adormitar los músculos de su reciente visitante. Las casas apenas pueden verse y los rostros de las personas se reconocen con dificultad entre la cortina blanquecina. El bus rojo que me transporta no tiene la misma tranquilidad de la neblina ni la pasividad del músculo contraído, serpentea velozmente entre los estrechos caminos que hacen las veces de

\footnotetext{
${ }^{1}$ Entendiendo el servir no de manera instrumental, sino de la puesta en escena de mi saber al servicio de los otros.

${ }^{2}$ Uso la metáfora de Borges para explicitar el uso de otro lenguaje -considerado único por demás- que se ha instaurado equivocadamente como insuperable garante de la objetividad y cientificidad. Desde ese lugar, entiendo una escritura desde el "no verso", escritura - desde un lenguaje particular- sin la cual no podría haber escrito este relato con validez académica.
} 
carretera. En su interior huele a fruta, huele a plátano, huele a cebolla. Atrás, van acomodados algunos viajeros con la carga natural para abastecer sus negocios, mientras tanto yo, en las sillas cercanas al conductor, reviso que aquel olor no se impregne en mi ropa ni en mi piel. Me huelo y acto seguido, me sacudo.

Continúa el trayecto, y ya pronto a llegar trato de identificar por uno de los vidrios llorosos del colectivo algunas pistas que me dieron: "luego de una cancha de futbol aparece un edificio, ahí se baja", "está ubicada muy cerca de una gran construcción”, “cuando el bus gire a la izquierda, atento". Mis pensamientos son acompasados por canciones de la emisora de música romántica La Voz de Colombia que el conductor canta con cierto dejo de nostalgia.

Las pistas para llegar a un lugar, lejos de ayudar al viajero primíparo lo que hacen es generar confusión. Cualquier terreno baldío me parece una cancha, tres ladrillos superpuestos se confunden con un edificio, y las calles se me antojan todas zurdas. Me dejo entonces guiar por el sentido común. En primer lugar, afino el oído: la bulla, la algarabía, los gritos, me ayudarán, pienso. Y segundo, agudizo la vista, un cartel en el que se lea: I.E. María de los Ángeles Cano Márquez, será la confirmación del sitio. Pues bien, es por boca de un señor de aspecto campesino que puedo encontrar la escuela luego de caminar por entre los caminos hechos laberintos del barrio. El sentido común, por lo menos esta vez, no estuvo de mi lado. Mejor, la solidaridad del anónimo amigo.

Medellín, comuna nororiental, comuna número uno, barrio Granizal. He llegado a la escuela. He llegado a mi escuela. El olor a cebolla desapareció, ahora huele a mar, o como diría mi hija: huele a pescado. Mi cuerpo gotea como la ventanilla del bus rojo y anuncia lo caminado, pero también la ansiedad de ingresar a la escuela en la que seguiré haciéndome maestro. Es enero. Todos los pensamientos, imágenes, anhelos y miedos previos a la llegada están contenidos en ese instante.

\section{De cómo se abren candados y corazones}

Maestro de escuela, eso soy. Los profesores de la Normal Superior de Medellín me lo recordaban diariamente. Ahora el vigilante de mi nueva escuela, don Delio, lo confirma: 
- Profe, bienvenido, lo estábamos esperando.

- Muchas gracias —respondo tímidamente.

- ¿Ustéd es el de Educación Física? - agrega para confirmar.

- Sí señor. ¡Soy yo!

- Bien pueda siga.

Accedo a la invitación de don Delio. Su baja estatura contrasta con su gran vozarrón. Cuando él habla las eses se hacen más grandes, su ascendencia campesina se revela en su voz. Comenzamos un breve recorrido por los interiores de la institución. "Este es el salón de biología, esta es la coordinación, esta es la sala de profesores, esta es la cancha, este es el salón de danzas". Cada lugar señalado por don Delio es provisto de algunos datos históricos. Cada rincón tiene su historia, cada rincón tiene su nombre. Como si fuera un amigo de años me pasea y enseña pacientemente todos los recintos escolares. Abre las puertas con gran experticia y señala aspectos puntuales que me pueden servir de orientación para mis prácticas pedagógicas y para la convivencia con otros profesores.

Así como don Delio abre candados y chapas para mostrar salones, me topé en mi etapa escolar con profesores que abrían simbólicamente el pecho para sacar corazones. Guillermino Lafuente ${ }^{3}$, profesor en secundaria, enseñaba y se ensañaba, proporcionaba lecciones y lesiones; especialista en momificar estudiantes, con maestría y doctorado en tácticas del miedo para fortalecer el "pensamiento crítico". Eso me aturdía. Recuerdo que una vez en una salida al planetario, iniciada la proyección, un Guillermino confundió las risas con desorden y, en plena función, me tomó por una oreja y me retiró del lugar. "¿Qué no le han enseñado las formas de comportarse, jovencito?", fue la sentencia final. Me dolió más la sacada sin razón y la anulación de mi voz que la oreja pellizcada.

Durante décadas en Colombia los dueños de la verdad han silenciado a otros. Coger por la oreja y poner el cañón en la cabeza tiene sus similitudes. Es una actitud que recuerda eliminar la diferencia por la fuerza. Los Guillerminos sí que saben de eso.

\footnotetext{
${ }^{3}$ Nombre del profesor que inspiraba un miedo terrible en el cuento Cuchilla (2000).
} 
Luego de caminar por todo el colegio, de mostrarme rincón por rincón, regreso al punto inicial de encuentro con mi fortuito profesor Delio. Ya no hace frío. Nos despedimos cordialmente, y antes de retirarme me dice con sus eses enormes: "bregue a coger el bus con tiempo para el lunes que empiezan las clases, pues en la mañana son más demoraditos. No se le olvide profesor Marco Fidel".

\section{4. ¡Levante la mano, expresidente!}

Como el número de golpes que le enseñó su padre para tocar la puerta, o como el número de avisos antes de ser castigado, tres veces se escuchó decir un nombre en el salón de clase. Nadie respondió. Ese nombre olía y sabía a grande y él, apenas era un niño.

Marco Fidel Suárez, ese pensaban que era yo. Nunca lo conocí, de hecho no me interesaba conocerlo, su nombre no parecía sonar apropiado para ningún amigo imaginario y menos para un niño de mi edad. Uno le pone a los amigos imaginarios nombres de superhéroes no de expresidentes. Supe quién era cuando alguna vez mi maestra me propuso contar su biografía en clase y yo, que no sabía decir que no, pues le dije que sí. Recuerdo que pasé varias tardes memorizando la biografía del famoso Marco Fidel Suárez, pues sabía que un discurso medianamente bien dicho en un acto cívico no pasaba a la historia, pero sí aquel en el que su protagonista lo olvidaba. La escuela a veces es cruel, así que, indiscutiblemente, era mejor no quedar en la historia y seguir siendo un rostro más en la muchedumbre escolar.

La retahíla de frases encadenadas era compleja, decía mucho más para la maestra que para mí, pero creo que salió medianamente bien. El premio fue un beso de mi maestra Marina Ramírez, acompañado de un "felicitaciones, Marco Fidel” y de algunos aplausos entusiasmados de mis compañeros - más por haber terminado que por la exuberancia del discurso.

Eso pasó cuando estaba en segundo grado. Ahora sabía que mi tocayo fue presidente de la república, y como no le bastaba con eso, fue intelectual, orador y poeta. Eso me pesaba porque yo también me llamo así: Marco Fidel. Y me pesaba aún más cuando me lo recordaban los profesores; pero pesaba en exceso — como los bultos de tierra 
que montaba a mis espaldas mi papá para construir una casita - porque era un nombre de un señor y yo solo era un niño. Recuerdo que cuando ingresaban los maestros a clase yo sabía que en su listado se encontraba, confundido entre otros nombres, el mío; y yo no quería que saliera, solo esperaba que se quedara escondido en la planilla. Finalmente, sin que ocurriera milagro alguno, no quedaba más que levantar la mano que duplicaba mi talla y mi pena_ para decir: “¡Presente!”

\section{Freinet y Lucho. Un encuentro casual}

Celestin Freinet, pedagogo francés, anhelaba una escuela sin muros. En la Normal Superior de Medellín me lo enseñaron, pero no lo comprendí hasta ese momento que acepté orientar el colectivo de maestros recién inaugurado. La pregunta envenenada del examen de pedagogía con el profesor Lucho se respondía sin tragedia doce años después: el proyecto que empezábamos permitía el rompimiento de los muros de nuestras escuelas, pues los educadores físicos podíamos vernos, podíamos hablar, podíamos pensar en conjunto, podíamos crear, podíamos saber qué sabíamos.

Luego de esa reunión, debíamos decidir el próximo encuentro.

- Entonces nos reunimos en mi institución, en San Pablo — dice María Torres.

- Hágale — responde el profesorado.

Quizá ella no lo sepa, pero su invitación tiene una connotación política, pues hace fisuras a unos marcos establecidos que desean atrapar a maestros y a estudiantes en espacios concretos y predeterminados. Los maestros de Educación Física se convierten en viajeros que conocen el barrio: la cancha de Granizal; las Instituciones Educativas de Orlando, de Robinson, de Gustavo, de Deisy y Jair, de Henry Arroyave y de Fernando, de Sandra, de Lina; el INDER de Ninson y de Rodolfo ${ }^{4}$.

Cuando el profe de Educación Física nos sacaba a caminar por el barrio yo no entendía para qué podía servir, me atrevo a decir que pocos lo entendían. Las raíces cuadradas y cubicas, el trinomio cuadrado perfecto y la función lineal se instalan como saberes sagrados en la escuela, el resto es herejía. Algunas prácticas tradicionales se

\footnotetext{
${ }^{4}$ Realmente las instituciones son de los maestros, no son el nombre que llevan puesto.
} 
vuelven tan duras que se incorporan en uno y cuesta quebrantarlas. Lo que decía la profe Sandra en su invitación era lo que el hereje de Educación Física en mi escuela ya pretendía: transgredir los rígidos espacios y tiempos escolares. Cambiar el olor a tiza por el olor a barrio, que a veces dice más que lo que se estampa en un tablero.

\section{Patos al agua}

Las voces del profesorado, muchas veces anuladas por decir la verdad o desfiguradas por reformas educativas de "avanzada", retumban en un salón. Cada voz es un grito, es una denuncia, reclama un saber, visibiliza un sujeto. "Ahhh... los profesores saben, ¡claro que los profesores saben!", advierto en silencio. Mientras eso pienso, una voz aguda ocupa lentamente cada rincón del salón. Una profesora de Básica Primaria, en plena reunión de educadores físicos, alza su voz dulcemente como aquel pájaro que gorjea en las mañanas.

Deisy, de figura menuda y voz melodiosa, que parece recién salida de algún reinado de belleza, comienza un relato cargado de entusiasmo. No sé cuántas veces ni a quiénes lo ha contado, pero cuando habla muestra el carácter de todas las buenas primeras veces: temor, alegría, entusiasmo, brillo en los ojos. Ella dice que "sus niños y niñas" — los que ha parido simbólicamente en un salón de clase - tienen la posibilidad de ir a una piscina en una de sus clases.

- La piscina es un plástico inflable que me presta uno de los padres de familia. Luego de la piscina, los niños y niñas pasan a una sesión de exfoliación donde tienen la posibilidad de masajearse unos a otros. Eso lo hacemos una vez al mes, y pueden participar los padres de familia de mis estudiantes — complementa en un discurso emotivo.

He ahí la esencia de la experiencia. Tocar el cuerpo del otro y de sí mismo. Las interacciones corporales se convierten en oportunidad para conocer a otros. El masaje es reivindicación de lo humano, subversión a la violencia cotidiana y refutación a una institucionalidad que niega el cuerpo. La profesora Deisy cuenta que su trabajo ha podido fundamentarlo teóricamente de a poco debido a una especialización que está haciendo. El miedo ha cedido un poco para dar paso al saber. 
Algunos tozudos detallan a los maestros como enfermos. El que se orina en la cama, el que tose sangre, el que mancha los interiores con sus desechos, es un enfermo porque no tiene el poder de la cura. Como un enfermo es visto muchas veces el maestro. En los congresos educativos hablan otros para salvarle del cáncer de la "ignorancia" que le carcome el cerebro. Olvidan algo esencial: aun sin tableros ni agua ni caminos ni techo les queda la voz a los maestros. Quizá no haya recursos, pero tampoco hay enfermedad. Mientras haya voz ningún síndrome lo aqueja.

Deisy sigue contando lo que hace con sus muchachos. $\mathrm{Su}$ voz se alza por los rincones del salón. Los hilos de sus palabras tejen un saber construido alrededor de una alberca casera y comunitaria. Ignoro lo que pensaban los otros maestros, pero a mí me impresionaba cada palabra de Deisy. Veo en su acto pedagógico una sutil resistencia, un sesudo y prodigioso testarazo al rígido conocimiento ¿Es posible construir saber en una alberca repleta de infantes, inundada más de gritos que de agua? ¿Es posible desde un juego pueril? Si se sacaran raíces cuadradas mientras nadan sería mejor para las "autoridades educativas", pues podrían mejorar los resultados de alguna prueba estandarizada, pero como juegan y contemplan sus cuerpos, quizá sirva de poco. Bajo nuestro mirada y nuestro saber ¡tanto qué sirve!, ¡tanto qué nos enseña la profe!, ¡tanto qué sabe!

- ¡Listo. Ya tenemos una ponente! — digo emocionado.

- ¿Cierto que es interesante mi propuesta?

- $\quad$ Más que eso, Deisy. Más que eso.

Deisy es una legítima diseñadora que a punta de manguera, piscina de plástico y jabones de colores crea experiencias transgresoras que le dan la espalda a la obviedad. Luego de verla en plena exposición, vestida de traje negro, de zapatilla orlada, como si se tratase de alguna gala especial, confirmo que la palabra de muchos maestros guarda saberes tan potentes que ningún agarrón de oreja puede borrar.

“Muchas gracias!” — dice Deisy. Ha terminado su exposición. Se escuchan los aplausos que parecen asemejarse al sonido que estampan los cuerpos de los niños en la alberca improvisada. 


\section{El trayecto continúa en la escuela de la cebolla}

La alberca de Deisy esconde en su vaivén aquellos nombres que me han agitado como maestro: Marleni Londoño (madre), Marco Gómez (padre), Rosita Arango, Cecilia Amaya, Marina Ramírez, Fabio Quinchía, Roberto Bustamante, Iván Uribe, Rubiela Arboleda, Patricia Álvarez, William Moreno, Lina Flórez, Gustavo Chaverra, Alejandro Vásquez Bernal, Néstor Díaz, Yolanda Zuluaga, Jaime Sierra y Oscar Henao.

La escuela de la cebolla ocupa gran parte de mi vida. Interactúo con la muchachada en la clase de Educación Física en la tarea imperecedera de construir una sociedad más digna. Mientras el frío conquista la montaña, camino al encuentro de estudiantes y maestros. Quizá mañana enfríe más lo montaña, mas no nuestro sueño de hacer una escuela justa y solidaria.

\section{Referencias bibliográficas}

Borges, J. (2015). Selección Cuentos, ensayos y poemas. Medellín: Universidad de Antioquia.

Rosero, E. (2000). Cuchilla. Bogotá: Norma. 